\title{
Messages Promoting Genetic Modification of Crops in the Context of Climate Change: Evidence for Psychological Reactance
}

\begin{abstract}
Genetic modification (GM) of crops and climate change are arguably two of today's most challenging science communication issues. Increasingly, these two issues are connected in messages proposing GM as a viable option for ensuring global food security threatened by climate change. This study examines the effects of messages promoting the benefits of GM in the context of climate change. Further, it examines whether explicit reference to "climate change," or "global warming" in a GM message results in different effects than each other, or an implicit climate reference. An online sample of U.S. participants $(\mathrm{N}=1,050)$ were randomly assigned to one of four conditions: "climate change" cue, "global warming" cue, implicit cue, or control (no message). Generally speaking, framing GM crops as a way to help ensure global food security proved to an effective messaging strategy in increasing positive attitudes toward GM. In addition, the implicit cue condition led to liberals having more positive attitudes and behavioral intentions toward GM than the "climate change" cue condition, an effect mediated by message evaluations. Keywords: Genetic modification, climate change, communication, political ideology, psychological reactance
\end{abstract}




\section{Introduction}

As the world population climbs toward 9 billion people by 2050, many have argued that the attendant growth in the demand for food poses a serious threat to global food security (Godfray et al., 2010; Hanjra \& Qureshi, 2010). Exacerbating this issue are the adverse effects of climate change, including water scarcity, pestilence, and impacts on crop productivity (Alcamo, Dronin, Endejan, Golubev, \& Kirilenko, 2007; Doll \& Siebert, 2002; Wheeler \& von Braun, 2013). Due to its potential to increase crop resistance to droughts, pests and diseases (Mannion \& Morse, 2012; Thirtle, Beyers, Ismael, \& Piesse, 2003), genetic modification (GM) of crops has been proffered as one viable approach to ensure the stability of global food security (Hanjra \& Qureshi, 2010; Qaim \& Kouser, 2013). Such approaches have been discussed in the mainstream media (e.g., Lynas, 2015) and amplified by big-name supporters, such as Bill Gates, quoted in an interview for the Wall Street Journal as stating,

"What are called GMOs are done by changing the genes of the plant... and it's pretty incredible because it reduces the amount of pesticide you need, raises productivity (and) can help with malnutrition by getting vitamin fortification...And so I think, for Africa, this is going to make a huge difference, particularly as they face climate change..." (McKay \& Blumenstein, 2015)

Even so, the American public's attitudes toward GM are far from positive. Although $88 \%$ American Association for the Advancement of Science members, most of whom are scientists, believe that GM foods are generally safe to eat, only $37 \%$ of the American public agree (Pew Research Center, 2015b) . Such opposition is a potential barrier to the development, production, and distribution of GM in crops given that government regulation and market success will 
largely rely on public acceptance (Bolsen, Druckman, \& Cook, 2014; Marques, Critchley, \& Walshe, 2015).

Substantial research has explored factors influencing attitudes toward GM (e.g., de Liver, van der Pligt, \& Wigboldus, 2005; McComas, Besley, \& Steinhardt, 2014; Prati, Pietrantoni, \& Zani, 2012). Importantly, many of these studies examined how message framing, a process by which an issue is described in a specific way (Chong \& Druckman, 2007), influences acceptance of GM (e.g., Druckman \& Bolsen, 2011; McFadden \& Lusk, 2015). Overall, these investigations suggest that providing information about GM's benefits plays a less vital role in influencing public attitudes than prior knowledge or preexisting beliefs (Fransen, Reinders, Bartels, \& Maassen, 2010; Frewer, Scholderer, \& Bredahl, 2003; Zhu \& Xie, 2015). This finding aligns with science communication research in general, which shows that preexisting beliefs or worldviews influence, to a large extent, how an individual selects, processes, or recalls controversial science issues (Jang, 2013; Kahan, Braman, Slovic, Gastil, \& Cohen, 2009). Many of these studies pinpointed worldview (e.g., political ideology, cultural cognitions, etc.) as influencing attitudes towards different science issues. However, less is known about how the same worldview influencing individuals' attitudes toward one controversial science issue may affect their attitudes toward another when the two issues are discussed together, which is the focus of our study.

Specifically, we investigate the effects of messages discussing the benefits of GM of crops to promote global food security in the context of climate change impacts. Building on literature in motivated reasoning and psychological reactance, we examine whether this context tends to strengthen or dampen message recipients' attitudes toward GM and intentions to consume GM foods. Further, building on previous research examining the effects of different 
labels on responses to questions about climate change, we examine whether message effects differ depending on whether the causes are attributed explicitly to "climate change", explicitly to "global warming", or only implicitly connected to climate change by describing the phenomenon without providing a label. Moreover, because political ideology has consistently been shown to influence response to climate change messages (e.g., Lu \& Schuldt, 2016), we investigate what role ideology may play in affecting reactions to GM messages explicitly or implicitly framed in the context of climate change. Finally, we examine underlying mechanisms for any potential differences in effects across messages.

\section{Effects of Information on Attitudes toward GM}

Prior research examining the effects of providing information about different aspects of GM on individuals' attitudes toward GM has yielded mixed results. Communicating the benefits of GM had little influence on consumers' attitudes (e.g., Frewer et al., 2003; Scholderer \& Frewer, 2003). In addition, mentioning multiple benefits of GM crops (e.g., health and environmental benefits) actually negatively influenced consumers' quality evaluation of the crops as compared to when only one of the benefits was conveyed (Heiman, 2014). In contrast, risk information about GM had a much stronger and more long-lasting effect on individuals' attitudes toward GM than benefit information (Zhu \& Xie, 2015). Many of these studies were oriented toward consumers and focused on benefits of GM directly accrued by consumers (e.g., lower price, healthful, better taste).

In the current study, we examine the effects of messages depicting the potential benefits of GM crops in helping fight against global food insecurity. Because of the reemergence of food security as an important issue globally, some scholars suggest that framing GM crops as a food security solution may be effective in increasing positive attitudes toward GM (Dibden, Gibbs, \& 
Cocklin, 2013). Indeed, public opinion research has shown that individuals are more positive about GM when used for crop disease resistance and to increase food supply in global contexts (Anunda, Njoka, \& Shauri, 2010; Frewer, Howard, \& Shepherd, 1997; Lusk, McFadden, \& Rickard, 2015; Priest, 2000). Therefore, we hypothesize:

H1: Exposure to a message promoting GM as a solution to global food insecurity will lead to more positive attitudes and behavioral intentions regarding GM as compared to no such exposure.

\section{Political Ideology and Climate Change Information Processing}

Individuals are biased information processors and do not always attend to arguments and evidence rationally and objectively (Taber \& Lodge, 2006). The idea of motivated reasoning refers to people's tendency to interpret and process incoming information in a way that serves to reinforce one's predispositions (Kunda, 1990). This phenomenon has been found across a variety of contexts, including individuals' reactions to controversial science issues (e.g., Druckman \& Bolsen, 2011; Nisbet, Cooper, \& Garrett, 2015).

In relation to climate change, research has consistently identified political ideology, one of many predispositions, as an important motivator for individuals' processing of climate change-related information both in the United States and many other countries (Hart \& Nisbet, 2012; Lu \& Schuldt, 2016; McCright, Dunlap, \& Marquart-Pyatt, 2016; Wiest, Raymond, \& Clawson, 2015). Studies have demonstrated that, in many countries across the world, people on the left side of political ideology (e.g., liberals in the United States) are more likely to believe in the existence and the anthropogenic cause of climate change and show stronger support for policies aimed at mitigating climate change; in comparison, people on the right side of political ideology (e.g., conservatives in the United States) exhibit less tendency to endorse these beliefs 
and policies (Kvaløy, Finseraas, \& Listhaug, 2012; McCright \& Dunlap, 2011; McCright et al., 2016; Tjernström \& Tietenberg, 2008).

Our current study focuses on the U.S. context, where opinions of climate change are highly politically polarized. The differences in views on climate change largely mirror the differences in values, beliefs, and ideals that fundamentally differentiate liberals and conservatives in the United States (Krosnick, Holbrook, \& Visser, 2000; McCright \& Dunlap, 2011). Therefore, upon encountering pro-climate change information, liberals tend to be more receptive of what this information advocates, while conservatives are more likely to show resistance to such information, a pattern consistent with the idea of motivated reasoning.

On a related note, when it comes to GM, research has not found a clear association between political ideology and attitudes toward GM (Kahan, 2015; Pew Research Center, 2015a). In other words, liberals and conservatives generally do not differ in their views on GM.

\section{The Explicit or Implicit Mention of Climate Change Cues}

Prior research has shown that attributing a natural disaster to climate change (vs. making no mention of climate change) made people with strong climate change skepticism less willing to help victims suffering from that disaster (Chapman \& Lickel, 2016) and that making no mention of climate change in a message increased climate adaptation intentions among individuals who were dismissive of climate change (Hine et al., 2016).

In the current study, we vary the messages based on whether they explicitly or implicitly mention climate change as causing the threat to global food security. Because attitudes toward GM are not hypothesized to be moderated by political ideology and we manipulate the explicitness of the climate change cue in the messages, we anticipate that after exposure to our experimental message, political ideology may influence individuals' attitudes toward GM crops 
in the same way as how political ideology influences attitudes toward climate change.

Particularly, given conservatives' tendency toward greater climate change skepticism, we hypothesize that

H2: Message conditions and political ideology will interact so that a message about GM mentioning climate change explicitly (vs. implicitly) will lead to more negative attitudes toward GM and weaker intentions to consume GM foods by conservatives.

For liberals, the story may be more complex. Persuasive messages do not always produce intended effects (e.g., increasing awareness, changing attitudes, modifying behaviors, etc.) and can sometimes have counteractive impacts (Hart, 2014). This is also likely the case when communicating about controversial science issues (Nisbet et al., 2015). One prominent theoretical framework that accounts for the counteractive effects produced by persuasive messages is psychological reactance (Brehm, 1966). According to this theory, individuals want to maintain freedom to choose their own behavior, and when that freedom is threatened, individuals will attempt to restore their freedom (Brehm, 1966). Research shows that when individuals perceive that a persuasive message constrains their freedom, they will likely try to restore freedom by engaging in attitudes or behaviors discouraged by the persuasive message (Brehm \& Brehm, 1981; Dillard \& Shen, 2005). The strength or intensity of language used in a persuasive message has been found to influence the extent to which psychological reactance emerges (Burgoon, Jones, \& Stewart, 1975; O'Keefe, 1997).

In relation to communicating about controversial science issues, psychological reactance is sometimes used to explain findings related to motivated reasoning (Nisbet et al., 2015; Schuldt \& Roh, 2014b). That is, when exposed to ideologically dissonant messages (e.g., conservatives coming across information advocating climate mitigation policies), psychological reactance may 
occur as a form of motivated reasoning and lead to counteractive responses (e.g., conservatives showing less support for climate mitigation policies) (Nisbet et al., 2015).

With respect to our study, both motivated reasoning and psychological reactance theory would predict that conservatives would have more positive reactions to a message promoting GM that only implicitly (vs. explicitly) mentions climate change, as we previously hypothesized (H2). However, for liberals, motivated reasoning and psychological reactance theory may offer contradictory predictions. Because "climate change" is a highly salient label among liberals (Jang \& Hart, 2015), a message that tries to persuade liberals to have more positive attitudes toward GM by explicitly using climate change as a crucial part of the argument may cause liberals to experience psychological reactance and act in a direction opposite to the message advocacy. The use of climate change in the message may be perceived by liberals as some form of manipulative language (Campbell, 1995), in that messages are deliberately playing to their climate change sympathies. On the other hand, because previous research has found that liberals are more accepting of the existence of climate change, explicitly mentioning climate change in the message could increase positive attitudes toward GM, a pattern consistent with motivated reasoning. Based on these opposing predictions in relation to how liberals may react to the climate change attribution in the GM messages, we propose two competing hypotheses: H3(a): Message conditions and political ideology will interact so that a message about GM mentioning climate change explicitly (vs. implicitly) will lead to more positive attitudes toward GM and stronger intentions to consume GM foods by liberals (the motivated reasoning account). H3(b): Message conditions and political ideology will interact so that a message about GM mentioning climate change explicitly (vs. implicitly) will lead to more negative attitudes toward 
GM and weaker intentions to consume GM foods by liberals (the psychological reactance account).

\section{Labeling the Cause as "Climate Change" vs. "Global Warming"}

How climate believers and skeptics respond to climate change information depends on not only the presence of a climate change cue in a message but also how it is labeled. An emerging line of research has focused on different ways of labeling climate change, and a critical part of this research compared how individuals reacted to the labels, "climate change" vs. "global warming” (e.g., Jaskulsky \& Besel, 2013; Leiserowitz et al., 2014; Schuldt, Konrath, \& Schwarz, 2011). Although the two labels have been used interchangeably, their scientific definitions are not the same. Global warming refers to the increase in the average surface temperature of the planet, whereas climate change is a broader concept encompassing a wider range of change including changes in precipitation patterns and sea levels (National Aeronautics and Space Administration, 2016). In addition, global warming implies human causes more strongly than climate change (Whitmarsh, 2008). While studies do not always find a consistent main effect of “climate change" vs. "global warming" on judgments and decision making, accumulating evidence indicates that the effects of the two labels rely on one's political ideology (Schuldt, Roh, \& Schwarz, 2015). Researchers have found that the two labels activate divergent patterns of cognitive accessibility across partisans: Although conservatives associate heat-related cues, such as rising temperatures and melting polar ice, more strongly with "global warming" than "climate change," liberals think about these concepts and images equally when exposed to either label (Schuldt \& Roh, 2014a). Because "global warming" and its associated heat-related cues involve a directional change in temperatures, and personal experiences with unusually cold weather can provide contradictory evidence, conservatives find it easier to discredit the existence of climate 
change when encountering the label, "global warming" (Schuldt \& Roh, 2014a; Weber \& Stern, 2011). Therefore, while the two labels are viewed similarly by liberals, "global warming" elicits less favorable reactions from conservatives (Schuldt et al., 2011; Schuldt et al., 2015). These results suggest that efforts seeking to elicit more positive reactions among conservatives to climate change information should use "climate change" instead of "global warming."

In relation to the current study, however, "global warming" may be more congruent with our messages, which emphasize the benefits of GM in making crops more resistant to increasingly common high-temperature events and droughts (Tester \& Langridge, 2010). Consequently, although conservatives more readily refute "global warming" than "climate change" in general, they may be less likely to do so in our current messaging context. This prediction is compatible with a recent labeling study showing that highlighting the consequences of "global warming" (vs. "climate change") on ocean temperature in relation to oyster health increased marine policy support from people with lower environmental values (McComas, Schuldt, Burge, \& Roh, 2015). Thus, we explore as a research question: RQ: How does attributing the causes to "climate change" vs. "global warming" influence attitudes toward GM and intentions to consume GM foods?

Finally, we also explore the underlying mechanisms accounting for potential interaction effects of message conditions and political ideology on individuals' attitudes toward GM and intentions to consume GM foods. We focus on negative message evaluations and anger as possible mediators for the psychological reactance prediction because research has demonstrated their role in explaining psychological reactance to persuasive messages (Dillard \& Shen, 2005; Rains, 2013). In terms of explaining motivated reasoning, while message evaluations can be used as a potential mediator, we also investigate the time spent reading the message and message 
processing fluency based on prior research suggesting that the extent to which deep processing, which is operationalized as how long it takes to read a message and how fluently one can process a message in our study, is adopted may be a reflection of motivated reasoning (Mullen \& Skitka, 2006). Therefore, we hypothesize:

H4(a): Message evaluation will mediate the relationship between message conditions and attitudes toward GM and intentions to consume GM foods, and political ideology will moderate these mediated relationships.

H4(b): Anger will mediate the relationship between message conditions and attitudes toward GM and intentions to consume GM foods, and political ideology will moderate these mediated relationships.

H4(c): Time spent reading the message will mediate the relationship between message conditions and attitudes toward GM and intentions to consume GM foods, and political ideology will moderate these mediated relationships.

H4(d): Message processing fluency will mediate the relationship between message conditions and attitudes toward GM and intentions to consume GM foods, and political ideology will moderate these mediated relationships.

In sum, our first objective is to assess the influence of exposure to messages about GM that place their use in the context of climate change on attitudes toward GM crops and intentions to consume GM foods. The second is to examine the effects of messages framing climate change in different ways (explicit mention of "climate change" vs. explicit mention of "global warming" vs. no explicit mention of either label, i.e., our implicit condition) on attitudes toward GM crops and intentions to consume GM foods. Importantly, we are especially interested in how political ideology may moderate the effects of these messages. Third, we explore potential mediators (i.e., 
anger, message evaluations, time spent reading the message, and message processing fluency) for any effects of messages on attitudes toward GM crops and intentions to consume GM foods, and examine whether the mediated relationships are moderated by political ideology. Essentially, we test for moderated mediation (Hayes, 2013). Finally, because our outcome variables include both attitudes toward GM and intentions to consume GM foods, we also explore the possibility that attitudes may mediate the effects of other variables on behavioral intentions, a prediction consistent with the theory of planned behavior (Ajzen, 1991; Figure 1).

\section{Methods}

\section{Participants}

We recruited 1,050 U.S. adults via the opt-in online survey Qualtrics panel in midNovember, 2015 (see Brandon, Long, Loraas, Mueller-Phillips, \& Vansant, 2014 for a description of the Qualtrics panel). Among the participants, $22.9 \%$ were male and $77.1 \%$ were female, with a mean age of 53.72 years $(S D=14.46)$. The median highest level of education was some college with no degree and median annual household income between $\$ 35,000-49,999$. The distribution of racial background among participants was: White $85.7 \%$, Black $6.6 \%$, Hispanic $3.4 \%$, Asian $1.9 \%$, and other $2.4 \%$. Being especially interested in how political ideology might interact with our experimental conditions, we recruited a sample with an equal number $(n=210)$ of participants in each of the following five categories: very liberal, somewhat

liberal, moderate, somewhat conservative, and very conservative to ensure a sufficient number of participants across the political spectrum. As a result, the sample's political ideology was balanced $(M=3.00, S D=1.42 ; 5$-point scale from $1=$ very liberal to $5=$ very conservative $)$. Each participant was randomly assigned to one of four experimental conditions. There were three 
message conditions: "climate change" cue $(n=273)$, "global warming" cue $(n=238)$, and implicit cue $(n=238)$, and one control, no message condition $(n=301)$.

\section{Procedure and Materials}

After giving informed consent, participants were randomly assigned to one of four conditions. Those assigned to one of the three message conditions proceeded to a page showing them the message and then answered questions related to the variables described in the following section. Those in the control condition proceeded directly to a similar survey without reading any message.

We developed messages based on scientific papers published in related fields (e.g., Azadi \& Ho, 2010; Godfray et al., 2010). The messages, approximately 120-words long, each stated that the global demand for food will increase rapidly in the next few decades and mentioned "rising temperatures and more severe droughts" as one of the reasons. Then the messages described GM as one potential tool to ensure food security. The messages differed only whether they attributed the context explicitly to "climate change," "global warming," or implicitly, which provided a description of the phenomenon but not specific label (see Appendix A for all the messages). Because weather-related cues were included even in the message that did not specifically mention either "climate change" or "global warming," we prefer to name this condition the implicit cue condition.

\section{Key Measures ${ }^{1}$}

Attitudes toward GM crops. Participants indicated their attitudes toward GM crops via eight semantic differential scales on a seven-point scale: unsafe-safe, useless-useful, positivenegative (reverse-coded), unpleasant-pleasant, environmentally unfriendly-environmentally friendly, unhealthy-healthy, disgusting-appealing, and frightening-reassuring (Fransen et al., 
2010). We created a composite scale by averaging the values of the eight items (Cronbach's $\alpha$ $=.97 ; M=3.51, S D=1.74)$.

Intentions to consume GM foods ${ }^{2}$. Participants indicated the extent to which they agreed or disagreed with three statements regarding their intentions to consume GM foods on a seven-point scale ( 1 = Strongly disagree and $7=$ Strongly agree $)$ : "I have no problems with eating food produced from genetically modified crops"; "When I know a food product contains genetically modified ingredients, I do not eat it" (reverse-coded); "When eating, I intend to make sure that my food does not contain genetically modified ingredients" (reverse-coded) (de Liver et al., 2005; Spence \& Townsend, 2006). The three items were averaged into a composite scale (Cronbach's $\alpha=.90 ; M=3.67, S D=1.82$ ).

Anger $^{3}$. Anger was assessed with four items: irritated, angry, annoyed and aggravated (Dillard \& Shen, 2005). Participants in the three message conditions were asked to indicate how much each of these emotions they felt when reading the message on a seven-point scale $(1=$ none of this feeling, $7=$ a lot of this feeling), whereas participants in the control condition were asked to indicate how much each of these emotions they are feeling at this moment on the same scale. A composite scale was created by averaging the values of the four items (Cronbach's $\alpha$ $=.94 ; M=2.93, S D=1.92)$.

Message evaluations. Participants indicated their message evaluations via six bipolar items on a seven-point scale: inaccurate-accurate, unfair-fair, untrustworthy-trustworthy, uncompelling-compelling, unpleasant-pleasant, and ineffective-effective (Dillard, Kinney, \& Cruz, 1996; Miller, Lane, Deatrick, Young, \& Potts, 2007; Rains \& Turner, 2007). These items were averaged to form a composite scale (Cronbach's $\alpha=.90 ; M=4.37, S D=1.45$ ). 
Time spent reading the message. We recorded the time (in seconds) participants spent reading the message $(M=59.94, S D=226.19)$. Participants were not aware that their reading time was being recorded.

Message processing fluency. Message processing fluency was measured using three items on a seven-point scale ( 1 = Strongly disagree and $7=$ Strongly agree $)$ : "The message was difficult to process"; "The message was easy to understand" (reverse-coded); "The message was difficult to comprehend" (Lee \& Aaker, 2004). We created a composite scale by averaging the three items (Cronbach's $\alpha=.85 ; M=2.27, S D=1.19$ ).

Manipulation check. We took two steps to examine whether our manipulations of the messages were successful. First, we included one question toward the end of the survey to examine whether participants in the "climate change" cue or the "global warming" cue conditions were more likely than participants in the implicit cue condition to notice that the message explicitly mentioned "climate change" or "global warming" as a factor that might influence food security. Specifically, this question asked, "Which of the following were mentioned in the message as factors that might threaten food security?" Five options were listed (“Growing population," "Increasing consumption," "Climate change (or Global warming)," “Overexploitation of natural resources," and "I don't recall”), and participants were free to choose as many answers as they liked. It should be noted that "climate change" was listed for participants in the "climate change" cue condition, while "global warming" was listed for those in the "global warming" cue condition. For participants in the implicit cue condition, participants were randomly provided with either "climate change" or "global warming" as an option.

Chi-square tests indicate that, compared to those in the implicit cue condition, participants in either the "climate change" cue condition, $\chi^{2}(1)=7.56, p<.01$, phi $=.12$, or the 
"global warming" cue condition, $\chi^{2}(1)=7.54, p<.01$, phi $=.13$, were more likely to agree that the message mentioned "climate change (or global warming)" as a potential factor influencing food security. Therefore, we deemed our manipulation of whether participants noticed the mention of climate change in the message successful.

Second, because we also needed to examine if participants in the "climate change" cue condition were more likely to notice the label they were exposed to was "climate change" (vs. "global warming") and if participants in the "global warming" cue condition were more likely to recognize the label used in their message was "global warming" (vs. "climate change"), we conducted a pretest of messages before conducting the study. We chose not to examine this manipulation in our main study because this examination would conflict with the previously discussed manipulation check question we included in the study. For the pretest, we recruited 64 participants from across the United States via Amazon's Mechanical Turk to evaluate the same messages used in the main study (see Paolacci \& Chandler, 2014 for a description of this participant pool). They were assigned to either the "climate change" cue condition $(n=33)$ or the "global warming" cue condition $(n=31)$. After exposure to the message and a series of questions that served as distraction, participants were asked which of the following was true for the message they just read: "The message specifically mentioned "climate change"”; "The message specifically mentioned 'global warming"”; "The message did not specifically mention 'climate change' or 'global warming",; "I don't recall."

The results of chi-square tests showed that participants in the "climate change" cue condition were more likely than those in the "global warming" cue condition to agree that the message explicitly mentioned "climate change," $\chi^{2}(1)=12.85, p<.001$, phi $=.45$, whereas participants in the "global warming" cue condition were more likely than those in the "climate 
change" cue condition to concur that the message made a specific mention of "global warming", $\chi^{2}(1)=21.33, p<.001, \mathrm{phi}=.58$. These results provided evidence that our manipulation of "climate change" vs. "global warming" cues was distinguishable by message recipients and provided added confidence that our manipulation would succeed in the main study.

\section{Data Analysis}

We employed ordinary least squares (OLS) regression as our primary statistical test to examine our hypotheses and research question. We used OLS regression rather than analysis of variance (ANOVA) to reduce the risk of type I and type II errors that can emerge when transforming continuous independent variables (e.g., political ideology) into categorical variables for ANOVA tests (Hayes, 2005). First, we tested the main effects of the experimental conditions on the two dependent variables, attitudes toward GM crops and intentions to consume GM foods, respectively. We created a number of OLS regression models featuring three dummy variables for the four experimental conditions (coded as 0 or 1), political ideology (centered), and control variables including sex $($ female $=0$, male $=1$ ), age, education (high school degree and below $=0$, above high school degree $=1)$, race $($ Non-white $=0$, White $=1)$ and household income $(\$ 50,000$ and below $=0$, above $\$ 50,000=1$ ) as the independent variables. Because we were interested in how the effects of each experimental condition differed from one another, we started our analyses with the control condition as the reference group and then used other conditions (i.e., "climate change" cue and "global warming" cue) as the reference group. Therefore, we built three regression models for each dependent variable.

Next, we examined the interaction effects of experimental conditions and political ideology on the two dependent variables, attitudes toward GM crops and intentions to consume GM foods, respectively. In addition to the independent variables included in the previous models 
examining the main effects of experimental conditions, the OLS regression models we built also included three two-way interaction terms between each of the three dummy variables and political ideology (i.e., the product of dummy variables and political ideology) as the independent variables. To probe for significant two-way interactions, following Aiken and West (1991), we tested for simple slope effects of the message conditions at one standard deviation below the mean of political ideology (referred to as liberals), the mean of political ideology (referred to as moderates), and one standard deviation above the mean of political ideology (referred to as conservatives).

Third, we used the PROCESS macro for SPSS (Model 8) for moderated mediation analyses as described in Hayes (2013). We excluded the control (no message) condition in our moderated mediation analyses because all the mediators we examined were related to the processing of a message, and these mediators were not included in the control condition survey. Except for variables involving the control condition, we included in the moderated mediation models the same independent variables as the previous OLS regression models examining the interaction effects of experimental conditions and political ideology. We included anger, message evaluations, time spent reading the message and message processing fluency as the mediator, respectively, and attitudes toward GM and intentions to consume GM foods as the dependent variable, respectively (5,000 bootstrap resamples, $95 \%$ bias corrected confidence interval).

Finally, we repeated the same moderated mediation analysis using attitudes toward GM as a mediator and behavioral intentions as the dependent variable. Then we adopted a procedure recommended by Hayes (2015) and employed a modified version of Model 6 in PROCESS to test for a moderated serial multiple mediation model in which the indirect effect of the two-way 
interaction of message conditions and political ideology on behavioral intentions to consume GM foods was carried through the mediator established in the step described in the last paragraph and then through attitudes toward GM (10,000 bootstrap resamples, 95\% bias corrected confidence interval).

\section{Results}

The results of our OLS regression models examining the main effects of experimental conditions show that, as compared to the control (no message) condition, the "climate change" cue condition $(B=.37, t=2.56, p<.05)$ and the implicit cue condition $(B=.46, t=3.12, p<.01)$ increased positive attitudes toward GM crops, and the implicit cue condition also enhanced intentions to consume GM foods $(B=.36, t=2.34, p<.05)$. In addition, as compared to the "global warming" condition, the implicit cue condition led to stronger intentions to consume GM foods $(B=.33, t=1.99, p<.05)$. In terms of the control variables, we found that, males showed more positive attitudes toward GM crops $(B=.62, t=4.83, p<.001)$ and stronger intentions to consume GM foods $(B=.73, t=5.44, p<.001)$ than females. Furthermore, individuals with a high school degree or above showed more positive attitudes toward GM crops than those without a high school degree $(B=.25, t=2.04, p<.05)$, and Whites showed stronger intentions to consume GM foods than other races $(B=.44, t=2.73, p<.01)$. Because only the implicit cue message increased both positive attitudes and behavioral intentions regarding GM as compared to the no message condition, H1 was only supported for the implicit cue condition.

Turning to our OLS regression models featuring the interaction terms between message conditions and political ideology (see Tables 1 and 2), we first examined if these models were significantly better than previous models without interaction terms (Aiken \& West, 1991). The results indicate that the model for attitudes toward GM crops, $F(3,1036)=2.48, p=.06$, and the 
model for intentions to consume GM foods, $F(3,1036)=2.15, p=.09$, were marginally significantly better than their corresponding models without interaction terms. Although the significance in change did not reach the conventional threshold $(p=.05)$, we chose to use models that included interaction terms for further analyses. This was because it is prudent in such cases to use a less conservative threshold (e.g., $p<.20)$ to reduce Type II errors associated with inappropriate dropping of variables (Cohen, Cohen, West, \& Aiken, 2002) and because these interaction models were built based on theoretical grounds.

In terms of attitudes toward GM crops, there was a significant two-way interaction between the implicit cue (vs. control, no message) condition and political ideology $(B=-.23, t=$ $-2.21, p<.05$; Model 1a in Table 1) such that after exposure to the implicit cue message (vs. no exposure at all $)$, liberals $\left(B=.76, t=3.75, p<.001 ; M_{\text {implicit }}=4.04, S E=.15\right.$ vs. $M_{\text {control }}=3.28$, $S E=.14)$ and moderates $\left(B=.43, t=2.87, p<.01 ; M_{\text {implicit }}=3.67, S E=.11\right.$ vs. $M_{\text {control }}=3.24$, $S E=.10)$ had more positive attitudes toward GM crops; there was no difference for conservatives. In addition, we found that when the "climate change" cue condition was the reference group (Model 1b in Table 1), there was a significant two-way interaction between implicit cue (vs. "climate change" cue) condition and political ideology, $B=-.26, t=-2.45, p$ $<.05$ (Figure 2). Specifically, liberals exhibited more positive attitudes toward GM crops after exposure to the implicit cue (vs. "climate change" cue) condition $\left(M_{\text {implicit }}=4.04, S E=.15\right.$ vs. $\left.M_{\text {climatechange }}=3.61, S E=.15\right), B=.43, t=2.10, p<.05$. No differences were found for moderates or conservatives.

In relation to intentions to consume GM foods, the results show a significant two-way interaction between the implicit cue (vs. control, no message) condition and political ideology $(B=-.23, t=-2.09, p<.05 ;$ Model 2a in Table 2) such that after exposure to the implicit cue 
message (vs. no exposure at all), liberals $\left(B=.66, t=3.11, p<.01 ; M_{\text {implicit }}=4.13, S E=.15\right.$ vs. $\left.M_{\text {control }}=3.47, S E=.15\right)$ and moderates $\left(B=.33, t=2.13, p<.05 ; M_{\text {implicit }}=3.84, S E=.12\right.$ vs. $M_{\text {control }}=3.51, S E=.10$ ) became more willing to consume GM foods, but there was no difference for conservatives. Additionally, when the reference group was the "climate change" cue condition, there was a significant two-way interaction between the implicit cue (vs. "climate change" cue) condition and political ideology, $B=-.24, t=-2.13, p<.05$ (Figure 3). Particularly, liberals were more willing to consume GM foods after exposure to the implicit cue (vs. "climate change" cue $)$ condition $\left(M_{\text {implicit }}=4.13, S E=.15\right.$ vs. $\left.M_{\text {climatechange }}=3.72, S E=.15\right), B=.41, t=$ $1.91, p=.06$. No differences were found for moderates or conservatives.

We briefly summarize here what these results mean for our hypotheses and research question. First, we hypothesized (H2) a significant interaction between message conditions and political ideology so that the implicit cue (vs. either "climate change" or "global warming" cue) message would lead to more positive attitudes toward GM crops and stronger intentions to consume GM foods among conservatives. However, we did not find evidence supporting H2. Thus, $\mathrm{H} 2$ was rejected. In terms of the competing hypotheses regarding whether a message about GM mentioning climate change explicitly (vs. implicitly) would either increase (H3a) or decrease ( $\mathrm{H} 3 \mathrm{~b}$ ) positive attitudes toward GM and intentions to consume GM foods by liberals, we found that the implicit cue (vs. "climate change" cue) message led to more positive attitudes toward GM and stronger intentions to consume GM foods among liberals. Therefore, H3(a) was rejected but H3(b) was supported for the "climate change" cue condition. Turning to our research question, we found no difference between the "climate change" cue and the "global warming" cue conditions in influencing individuals' attitudes or behavioral intentions concerning GM. Nor 
did we find that political ideology moderated the effects of "climate change" cue (vs. "global warming" cue) condition on attitudes or behavioral intentions.

The last set of hypotheses was related to the mediating role of message evaluation (H4a), anger $(\mathrm{H} 4 \mathrm{~b})$, time spent reading the message $(\mathrm{H} 4 \mathrm{c})$ and message processing fluency $(\mathrm{H} 4 \mathrm{~d})$. Because we found a significant two-way interaction of the implicit cue (vs. "climate change" cue) condition and political ideology on attitudes toward GM and intentions to consume GM foods, we examined if the four proposed variables mediated the relationship between the implicit cue (vs. "climate change" cue) condition and attitudes and intentions, and whether political ideology moderated these mediated relationships. The index of moderated mediation is shown in Table 3 (Hayes, 2015). Particularly, we found only that message evaluations fully mediated the effect of the implicit cue (vs. "climate change" cue) condition on attitudes toward GM crops and intentions to consume GM foods, and this mediation was moderated by political ideology. Thus, H4a was supported, but $\mathrm{H} 4 \mathrm{~b}, \mathrm{H} 4 \mathrm{c}$, and $\mathrm{H} 4 \mathrm{~d}$ were rejected.

To further test if attitudes toward GM served as a mediator between other variables and behavioral intentions, we first established that attitudes fully mediated the effect of the implicit cue (vs. "climate change" cue) condition on behavioral intentions and this mediation was moderated by political ideology (see Tables 3 and 4). Then the results of our moderated serial multiple mediation model show that the serial indirect effect of the implicit cue (vs. "climate change" cue) condition through both message evaluations and attitudes on behavioral intentions was moderated by political ideology because the confidence intervals did not overlap with zero (see Figure 4). However, the indirect effects of the implicit cue (vs. "climate change" cue) condition through message evaluations alone or through attitudes alone on behavioral intentions were not significant in this model. Altogether, these findings suggest that liberals evaluated the 
implicit cue message more positively than the "climate change" cue message, which led to more positive attitudes toward GM crops and in turn generated stronger intentions to consume GM foods.

\section{Discussion}

With more widespread recognition of the potential threats climate change poses to global food security (Calzadilla et al., 2013; Wheeler \& von Braun, 2013), increasing attention is being given to identifying possible ways to reduce those threats (VijayaVenkataRaman, Iniyan, \& Goic, 2012). This includes communication efforts focused on reducing vulnerability to climate change (Moser, 2010). In this context, some efforts have suggested GM as a way to ensure global food security in the face of climate change. Yet, public opinion on the use of GM remains mixed, as do U.S. views toward climate change.

This confluence of potentially challenging science communication issues led us to pose an empirically relevant yet unexplored question: Does mentioning climate change and its threats to global food security in a message about the use of GM in agriculture increase positive attitudes toward GM crops and intentions to consume GM foods? Importantly, we embedded this research question into a broader literature on how individuals react to controversial science topics that may trigger different psychological tendencies and furthered our inquiry by building upon research on motivated reasoning and psychological reactance.

We found that, generally speaking, messages that promoted GM as a useful tool in combating global food insecurity led to more favorable attitudes toward GM. Our results showed that two of the three messages, regardless of whether they attributed the cause explicitly to climate change or simply rising temperature and droughts, made people more positive about GM crops as compared to the no message condition. Consistent with our hypothesis, it may be that 
the idea of tackling global food security resonates with people's moral values. Evidence suggests that moral and ethical concerns regarding GM are particularly important for consumers in North America (Frewer et al., 2013). While the primary discussion surrounding the moral aspects of GM tends to focus on the negative side of the technology (Finucane \& Holup, 2005), reconstituting GM as a moral imperative to help ensure global food security may be an efficacious messaging strategy for those wishing to increase positive attitudes for GM (Dibden et al., 2013). Such a recommendation is bolstered by public opinion research that has found more favorable attitudes toward GM used for enhancement of food supplies in certain nations (e.g., Anunda et al., 2010). Future research could examine this relationship and its practical and ethical implications further.

Although the effects of socio-demographic variables were not a primary pursuit of our study, we found that gender, race and education influenced attitudes and/or behavioral intentions regarding GM. Being male and White, and having a high school degree or above were associated with more positive views of GM. These findings echo existing public opinion research on this topic (Pew Research Center, 2015a). Understanding the influences of such socio-demographic information on GM attitudes can help develop more effective targeted communication strategies (Frewer et al., 2013).

Our study also investigated how individuals with disparate political ideologies reacted to GM messages featuring different labeling of climate change. We relied on motivated reasoning and psychological reactance theory to predict how messages might influence liberals' attitudes toward GM. In contrast with motivated reasoning yet consistent with the theory of psychological reactance, we found that liberals reacted less positively after exposure to the message that made an explicit (vs. implicit) mention of climate change. This finding is somewhat surprising 
considering a substantial amount of research has identified liberals as strong climate change proponents (McCright \& Dunlap, 2011), yet it does align with other work showing that messages linking natural crises explicitly (vs. not) to climate change did not always prove to be more receptive among liberals (Lu \& Schuldt, 2016).

One speculation is that because all our messages included weather-related descriptions, our participants might have automatically associated these weather-related impacts with climate change. Therefore, specifically mentioning climate change in the message in an effort to bolster favorable responses from liberals may not be fruitful as these participants may make that implicit connection whether or not the particular term appears in the message. In a similar vein, this conjecture may also explain why there was no difference in how conservatives responded to the messages - that is, climate change was implied if not mentioned explicitly. Future research may seek to explore how likely it is for liberals and conservatives to associate weather-related descriptions with climate change.

Because we observed a boomerang effect for liberals from the message condition that specifically used the label, "climate change," a pattern predicted by the psychological reactance theory, we speculate that the label, "climate change," might have been regarded by liberals as some kind of controlling language that threatened their freedom to choose and act. This assumption is likely as future harsh weather is cited as one critical factor endangering global food security, which lays the foundation for the pro-GM argument. Adding the "climate change" cue to the message may have been akin to overkill, making the message appear too manipulative to liberals. It should be noted that this reactance only emerged for "climate change" and not "global warming." This differential result might be attributed partly to the "climate change" cue being a more widely-used and thus more salient term among liberals (Jang \& Hart, 2015). The 
explicitness of the controlling language used in a message can affect the extent to which psychological reactance occurs (Miller et al., 2007). For liberals, the explicitness of the controlling or manipulative intent conveyed by the "climate change" cue might have been greater than the "global warming" cue. Future research could investigate situations when the use of ideologically consistent cues is perceived as manipulative and leads to counteractive results.

Although we did not assess the perceived explicitness of the manipulative intent of the message, our measure of message evaluations might help untangle at least part of the story. We found that message evaluations served as a significant mediator explaining why liberals experienced psychological reactance in the "climate change" cue condition. When liberals read the message with the "climate change" cue, they reacted less positively to the message than when exposed to a message without any mention of "climate change." This is consistent with previous work, supporting the role of cognitive appraisals of messages as one manifestation of psychological reactance (Dillard \& Shen, 2005).

Although anger is also proposed as one component of psychological reactance, we did not establish its mediating role in our study, echoing some other work in this domain (e.g., LaVoie, Quick, Riles, \& Lambert, 2015). This is perhaps because our messages were not designed to be emotionally engaging and the differences between messages were so subtle that no meaningful differences in the levels of felt anger emerged.

In terms of the other mediator in our final model, although we did not intend to examine empirically the theory of planned behavior, attitudes toward GM crops accounted for the bulk of the behavioral intention construct. Practically speaking, this suggests that to change people's behaviors regarding GM products, focusing on addressing factors that influence attitudes can be an efficacious approach. 
Another goal of our study was to examine whether conservatives would react differently to labels. In contrast to prior research (Schuldt et al., 2011; Schuldt et al., 2015), we did not find a significant two-way interaction of the "climate change" (vs. "global warming") label and political ideology on our outcome variables. Several differences between our study and previous studies may explain the dissimilar findings. First, unlike previous studies that focused on the differential effects of "climate change" vs. "global warming" on climate-related perceptions and judgments, our study emphasized how these two labels influenced GM-related attitudes and behavioral intentions. Whereas we expected that worldviews (e.g., political ideology) associated with climate change could motivate individuals to think about other issues that were linked, at least superficially, to climate change, we did not find evidence for such motivated reasoning.

Second, prior research that found disparate effects of "climate change" vs. "global warming" did not provide a particular context or specific impacts when mentioning either label (e.g., Schuldt et al., 2015). In contrast, the messages used in our study associated rising temperatures and severe droughts with "climate change" or "global warming." While conservatives may more readily reject the "global warming" label (Schuldt \& Roh, 2014a), it may be more difficult to do so in our current messaging context as the impacts mentioned in the messages are congruent with the heat-related idea implied by "global warming." Future research should continue to explore to what extent particular contexts or impacts matter when climate skeptics process information containing global warming cues.

We should also note some limitations of our study. First, because we did not use a representative sample of the U.S. population, our findings are not generalizable. Nevertheless, we included a fairly diverse sample of participants across the United States. Although the sample was skewed toward females and Whites, we controlled for these factors and other basic 
demographic variables in our models. Further, it should be noted that our primary interest lied in testing the experimental effects of different conditions, and the randomized, between-subjects design of our study should be able to help limit effects of non-focal factors on our key dependent variables. Future research would benefit from recruiting a nationally representative sample to fully assess how the findings from this study may be generalized. Moreover, our study is heavily rooted in the U.S. context. However, it should be noted that similar political divides on climate change exist in many other countries (McCright et al., 2016). It would be valuable for future research to compare the effects of these messages and the role of political ideology in other countries.

In addition, we did not include any direct measure assessing if participants agreed that GM was indeed a valuable solution to global food insecurity, and our message evaluations measure was not sufficient to address this issue. The message evaluations measure was a general measure for gauging individuals' evaluation of the message as a whole. It was not intended as a measure for evaluating the particular argument for the usefulness of GM in fighting threats from climate change per se, despite the fact that this was the central point of the message. One alternative explanation for why the "climate change" cue message was less receptive among liberals could be that while liberals were supportive of actions toward addressing climate change, they would be more likely to endorse mitigation actions that more actively address climate change than adaptation approaches like GM of crops (Newman, 2015). Furthermore, because liberals show more concern about climate change and arguably know more about climate change (Leiserowitz \& Smith, 2010), they might more readily come up with alternative solutions to climate change-threatened global food security other than GM and appreciate alternative solutions more. Future research should seek to examine if attitudes toward the effectiveness or 
appropriateness of using GM in combating climate change factor into individual responses to these messages.

In conclusion, our study demonstrates that messages linking GM to global food security generally seem to increase favorable attitudes toward GM crops, irrespective of whether the weather-related problems mention climate change. Returning to our real-world example from the study's introduction, these findings would suggest that Bill Gates' statement in the Wall Street Journal linking GM to food security in Africa in the context of climate change might indeed have led to increased support for GM's use, even among the more conservative readership of the Wall Street Journal (Feldman, Hart, \& Milosevic, 2015). However, among certain sub-groups, particularly liberals, our results suggest that the same statement from Bill Gates might appeal less, given that our findings show that the explicit mention of "climate change" in our message resulted in less favorable attitudes among liberals than the implicit mention. To be sure, our intent was not to test out any one individual's statement about GM or climate change but rather to explore how the intersection of oft-times controversial science issues can lead to different effects of science communication efforts. Our results confirm that even subtle cues in message content can shift people's attitudes toward GM and intentions to consumer GM foods, thus reinforcing the need for nuanced message testing to ensure that the intended effects of science communication efforts align with the observed outcomes. 


\section{Notes}

${ }^{1}$ We also measured support for climate mitigation policies (e.g., "Require fossil fuel companies to pay a carbon tax") and behavioral intentions to adopt environmentally friendly behaviors (e.g., "Carpool and drive less by using public transportation, bicycles, or walking more often”). Although political ideology was significantly correlated with these two variables in a way consistent with prior research — that is, liberals were more supportive of these policies and behaviors, there was no main effect of experimental conditions or interaction effects of experimental conditions and political ideology on these two variables.

${ }^{2}$ We conducted confirmatory factor analyses following Kline's (2015) recommendations to examine if discriminant validity exists between attitudes toward GM crops and behavioral intentions to consume GM foods. We conducted a chi-square difference test comparing the chisquare difference between a two-factor model and a one-factor model. The results indicate that the two variables have discriminant validity, $\chi_{\text {difference }}^{2}=523.09, \mathrm{df}_{\text {difference }}=1$.

${ }^{3}$ We also measured fear ("afraid"), sadness ("sad"), disgust (“disgusted"), hope ("hopeful") and excitement ("excited"). These emotions were used mostly as distraction items so that participants would not focus merely on anger. We did not find any significant main effects of the message conditions or two-way interaction effects between message conditions and political ideology on these emotions. 


\section{References}

Aiken, L. S., \& West, S. G. (1991). Multiple regression: Testing and interpreting interactions. Thousand Oaks, CA: Sage.

Ajzen, I. (1991). The theory of planned behavior. Organizational behavior and human decision processes, 50(2), 179-211.

Alcamo, J., Dronin, N., Endejan, M., Golubev, G., \& Kirilenko, A. (2007). A new assessment of climate change impacts on food production shortfalls and water availability in Russia. Global Environmental Change, 17(3-4), 429-444. doi:10.1016/j.gloenvcha.2006.12.006

Anunda, H., Njoka, F., \& Shauri, S. (2010). Assessment of Kenyan public perception on genetic engineering of food crops and their products. Journal of Applied Biosciences, 33, $2027-$ 2036.

Azadi, H., \& Ho, P. (2010). Genetically modified and organic crops in developing countries: a review of options for food security. Biotechnol Adv, 28(1), 160-168. doi:10.1016/j.biotechadv.2009.11.003

Bolsen, T., Druckman, J. N., \& Cook, F. L. (2014). How Frames Can Undermine Support for Scientific Adaptations: Politicization and the Status-Quo Bias. Public Opinion Quarterly, 78(1), 1-26. doi:10.1093/poq/nft044

Brandon, D. M., Long, J. H., Loraas, T. M., Mueller-Phillips, J., \& Vansant, B. (2014). Online Instrument Delivery and Participant Recruitment Services: Emerging Opportunities for Behavioral Accounting Research. Behavioral Research in Accounting, 26(1), 1-23. doi:10.2308/bria-50651

Brehm, J. W. (1966). A theory of psychological reactance. New York,: Academic Press.

Brehm, J. W., \& Brehm, S. (1981). Psychological Reactance: A Theory of Freedom and Control. Mahwah, NJ: Erlbaum.

Burgoon, M., Jones, S. B., \& Stewart, D. (1975). Towards a message-centered theory of Persuasion: Three empirical investigations of language intensity. Human Communication Research, 1(3), 240-256. doi:10.1111/j.1468-2958.1975.tb00271.x

Calzadilla, A., Rehdanz, K., Betts, R., Falloon, P., Wiltshire, A., \& Tol, R. S. J. (2013). Climate change impacts on global agriculture. Climatic Change, 120(1-2), 357-374. doi:10.1007/s10584-013-0822-4

Campbell, M. (1995). When Attention-Getting Advertising Tactics Elicit Consumer Inferences of Manipulative Intent: The Importance of Balancing Benefits and Investments. Journal of Consumer Psychology, 4(3), 225-254. doi:10.1207/s15327663jcp0403_02

Chapman, D. A., \& Lickel, B. (2016). Climate Change and Disasters: How Framing Affects Justifications for Giving or Withholding Aid to Disaster Victims. Social Psychological and Personality Science, 7(1), 13-20. doi:10.1177/1948550615590448

Chong, D., \& Druckman, J. N. (2007). Framing theory. Annual Review of Political Science, 10, 103-126. doi:10.1146/annurev.polisci.10.072805.103054

Cohen, J., Cohen, P., West, S. G., \& Aiken, L. S. (2002). Applied multiple regression/correlation analysis for the behavioral sciences (3rd ed. ed.). Mahwah, NJ: Lawrence Erlbaum Associates.

de Liver, Y., van der Pligt, J., \& Wigboldus, D. (2005). Unpacking atitudes towards genetically modified food. Appetite, 45(3), 242-249. doi:10.1016/j.appet.2005.07.004

Dibden, J., Gibbs, D., \& Cocklin, C. (2013). Framing GM crops as a food security solution. Journal of Rural Studies, 29, 59-70. doi:10.1016/j.jrurstud.2011.11.001 
Dillard, J. P., Kinney, T. A., \& Cruz, M. G. (1996). Influence, appraisals, and emotions in close relationships. Communication Monographs, 63(2), 105-130.

Dillard, J. P., \& Shen, L. (2005). On the Nature of Reactance and its Role in Persuasive Health Communication. Communication Monographs, 72(2), 144-168. doi:10.1080/03637750500111815

Doll, P., \& Siebert, S. (2002). Global modeling of irrigation water requirements. Water Resources Research, 38(4). doi:Artn 103710.1029/2001wr000355

Druckman, J. N., \& Bolsen, T. (2011). Framing, Motivated Reasoning, and Opinions About Emergent Technologies. Journal of Communication, 61(4), 659-688. doi:10.1111/j.14602466.2011.01562.x

Feldman, L., Hart, P. S., \& Milosevic, T. (2015). Polarizing news? Representations of threat and efficacy in leading US newspapers' coverage of climate change. Public Understanding of Science, 0963662515595348.

Finucane, M. L., \& Holup, J. L. (2005). Psychosocial and cultural factors affecting the perceived risk of genetically modified food: an overview of the literature. Soc Sci Med, 60(7), 16031612. doi:10.1016/j.socscimed.2004.08.007

Fransen, M. L., Reinders, M. J., Bartels, J., \& Maassen, R. L. (2010). The influence of regulatory fit on evaluation and intentions to buy genetically modified foods: The mediating role of social identification. Journal of Marketing Communications, 16(1-2), 5-20. doi:10.1080/13527260903342696

Frewer, L. J., Howard, C., \& Shepherd, R. (1997). Public concerns in the United Kingdom about general and specific applications of genetic engineering: Risk, benefit, and ethics. Science, technology \& human values, 22(1), 98-124.

Frewer, L. J., Scholderer, J., \& Bredahl, L. (2003). Communicating about the risks and benefits of genetically modified foods: The mediating role of trust. Risk Analysis, 23(6), 11171133. doi:DOI 10.1111/j.0272-4332.2003.00385.x

Frewer, L. J., van der Lans, I. A., Fischer, A. R. H., Reinders, M. J., Menozzi, D., Zhang, X., . . . Zimmermann, K. L. (2013). Public perceptions of agri-food applications of genetic modification - A systematic review and meta-analysis. Trends in Food Science \& Technology, 30(2), 142-152. doi:10.1016/j.tifs.2013.01.003

Godfray, H. C., Beddington, J. R., Crute, I. R., Haddad, L., Lawrence, D., Muir, J. F., . . . Toulmin, C. (2010). Food security: the challenge of feeding 9 billion people. Science, 327(5967), 812-818. doi:10.1126/science.1185383

Hanjra, M. A., \& Qureshi, M. E. (2010). Global water crisis and future food security in an era of climate change. Food Policy, 35(5), 365-377. doi:10.1016/j.foodpol.2010.05.006

Hart, P. S. (2014). Boomerang effects in risk communication. In J. Arvai \& L. Rivers III (Eds.), Effective Risk Communication (pp. 304-318). New York, NY: Routledge.

Hart, P. S., \& Nisbet, E. C. (2012). Boomerang Effects in Science Communication: How Motivated Reasoning and Identity Cues Amplify Opinion Polarization About Climate Mitigation Policies. Communication Research, 39(6), 701-723. doi:10.1177/0093650211416646

Hayes, A. F. (2005). Statistical Methods for Communication Science. Mahwah, NJ: Lawrence Erlbaum Associates.

Hayes, A. F. (2013). Introduction to mediation, moderation, and conditional process analysis: A regression-based approach: Guilford Press. 
Hayes, A. F. (2015). An index and test of linear moderated mediation. Multivariate Behavioral Research, 50(1), 1-22.

Heiman, A. (2014). The effect of information regarding multi-attributes on consumers' choices of GM products. Environment and Development Economics, 19(06), 769-785. doi:10.1017/s1355770x14000412

Hine, D. W., Phillips, W. J., Cooksey, R., Reser, J. P., Nunn, P., Marks, A. D. G., . . Watt, S. E. (2016). Preaching to different choirs: How to motivate dismissive, uncommitted, and alarmed audiences to adapt to climate change? Global Environmental Change, 36, 1-11. doi:10.1016/j.gloenvcha.2015.11.002

Jang, S. M. (2013). Seeking Congruency or Incongruency Online?: Examining Selective Exposure to Four Controversial Science Issues. Science Communication, 36(2), 143-167. doi:10.1177/1075547013502733

Jang, S. M., \& Hart, P. S. (2015). Polarized frames on "climate change" and "global warming" across countries and states: Evidence from Twitter big data. Global Environmental Change, 32, 11-17. doi:10.1016/j.gloenvcha.2015.02.010

Jaskulsky, L., \& Besel, R. (2013). Words That (Don't) Matter: An Exploratory Study of Four Climate Change Names in Environmental Discourse. Applied Environmental Education \& Communication, 12(1), 38-45. doi:10.1080/1533015x.2013.795836

Kahan, D. M. (2015). Climate-Science Communication and the Measurement Problem. Political Psychology, 36, 1-43. doi:10.1111/pops.12244

Kahan, D. M., Braman, D., Slovic, P., Gastil, J., \& Cohen, G. (2009). Cultural cognition of the risks and benefits of nanotechnology. Nat Nanotechnol, 4(2), 87-90. doi:10.1038/nnano.2008.341

Kline, R. B. (2015). Principles and practice of structural equation modeling. New York, NY: Guilford publications.

Krosnick, J. A., Holbrook, A. L., \& Visser, P. S. (2000). The impact of the fall 1997 debate about global warming on American public opinion. Public Understanding of Science, 9(3), 239-260. doi:Doi 10.1088/0963-6625/9/3/303

Kunda, Z. (1990). The Case for Motivated Reasoning. Psychological Bulletin, 108(3), 480-498. doi:Doi 10.1037//0033-2909.108.3.480

Kvaløy, B., Finseraas, H., \& Listhaug, O. (2012). The publics' concern for global warming: A cross-national study of 47 countries. Journal of Peace Research, 49(1), 11-22.

LaVoie, N. R., Quick, B. L., Riles, J. M., \& Lambert, N. J. (2015). Are Graphic Cigarette Warning Labels an Effective Message Strategy? A Test of Psychological Reactance Theory and Source Appraisal. Communication Research, 0093650215609669.

Lee, A. Y., \& Aaker, J. L. (2004). Bringing the frame into focus: The influence of regulatory fit on processing fluency and persuasion. Journal of personality and social psychology, 86(2), 205-218. doi:10.1037/0022-3514.86.2.205

Leiserowitz, A., Feinberg, G., Rosenthal, S., Smith, N., Anderson, A., Roser-Renouf, C., \& Maibach, E. (2014). What's In A Name? Global Warming vs. Climate Change. Retrieved from http://environment.yale.edu/climate-communicationOFF/files/Global_Warming_vs_Climate_Change_Report.pdf

Leiserowitz, A., \& Smith, N. (2010). Knowledge of Climate Change Across Global Warming's Six Americas. Retrieved from http://climatecommunication.yale.edu/wpcontent/uploads/2016/02/2010_12_Knowledge-of-Climate-Change-Across-GlobalWarming\%E2\%80\%99s-Six-Americas.pdf 
Lu, H., \& Schuldt, J. P. (2016). Compassion for climate change victims and support for mitigation policy. Journal of Environmental Psychology, 45, 192-200. doi:10.1016/j.jenvp.2016.01.007

Lusk, J. L., McFadden, B. R., \& Rickard, B. J. (2015). Which biotech foods are most acceptable to the public? Biotechnology journal, 10(1), 13-16.

Lynas, M. (2015). How I Got Converted to G.M.O. Food. The New York Times. Retrieved from http://www.nytimes.com/2015/04/25/opinion/sunday/how-i-got-converted-to-gmofood.html? r=1

Mannion, A. M., \& Morse, S. (2012). Biotechnology in agriculture: Agronomic and environmental considerations and reflections based on 15 years of GM crops. Progress in Physical Geography, 36(6), 747-763. doi:10.1177/0309133312457109

Marques, M. D., Critchley, C. R., \& Walshe, J. (2015). Attitudes to genetically modified food over time: How trust in organizations and the media cycle predict support. Public Underst Sci, 24(5), 601-618. doi:10.1177/0963662514542372

McComas, K. A., Besley, J. C., \& Steinhardt, J. (2014). Factors influencing U.S. consumer support for genetic modification to prevent crop disease. Appetite, 78, 8-14. doi:10.1016/j.appet.2014.02.006

McComas, K. A., Schuldt, J. P., Burge, C. A., \& Roh, S. (2015). Communicating about marine disease: The effects of message frames on policy support. Marine Policy, 57, 45-52. doi:10.1016/j.marpol.2015.02.012

McCright, A. M., \& Dunlap, R. E. (2011). The Politicization of Climate Change and Polarization in the American Public's Views of Global Warming, 2001-2010. Sociological Quarterly, 52(2), 155-194. doi:10.1111/j.1533-8525.2011.01198.x

McCright, A. M., Dunlap, R. E., \& Marquart-Pyatt, S. T. (2016). Political ideology and views about climate change in the European Union. Environmental Politics, 25(2), 338-358.

McFadden, B. R., \& Lusk, J. L. (2015). Cognitive biases in the assimilation of scientific information on global warming and genetically modified food. Food Policy, 54, 35-43. doi:10.1016/j.foodpol.2015.04.010

McKay, B., \& Blumenstein, R. (2015). Gates Foundation Sees a Better Future Driven by Technology. The Wall Street Journal. Retrieved from http://www.wsj.com/articles/gatesfoundation-sees-a-better-future-driven-by-technology-1421900245

Miller, C. H., Lane, L. T., Deatrick, L. M., Young, A. M., \& Potts, K. A. (2007). Psychological Reactance and Promotional Health Messages: The Effects of Controlling Language, Lexical Concreteness, and the Restoration of Freedom. Human Communication Research, 33(2), 219-240. doi:10.1111/j.1468-2958.2007.00297.x

Moser, S. C. (2010). Communicating climate change: history, challenges, process and future directions. Wiley Interdisciplinary Reviews-Climate Change, 1(1), 31-53. doi:10.1002/wcc.011

Mullen, E., \& Skitka, L. J. (2006). Exploring the psychological underpinnings of the moral mandate effect: motivated reasoning, group differentiation, or anger? J Pers Soc Psychol, 90(4), 629-643. doi:10.1037/0022-3514.90.4.629

National Aeronautics and Space Administration. (2016). What's the difference between climate change and global warming? Retrieved from http://climate.nasa.gov/faq/

Newman, C. (Producer). (2015). Liberals want to mitigate climate change, conservatives to adapt to it, according to study. Retrieved from http://phys.org/news/2015-11-liberals-mitigateclimate.html 
Nisbet, E. C., Cooper, K. E., \& Garrett, R. K. (2015). The Partisan Brain: How Dissonant Science Messages Lead Conservatives and Liberals to (Dis)Trust Science. Annals of the American Academy of Political and Social Science, 658(1), 36-66. doi:10.1177/0002716214555474

O'Keefe, D. J. (1997). Argumentative candor and persuasive success: A meta-analysis of the persuasive effects of implicit and explicit message conclusions. In J. F. Klumpp (Ed.), Argument in a time of change: Definitions, frameworks, and critiques (pp. 63-69). Annandale, VA: National Communication Association.

Paolacci, G., \& Chandler, J. (2014). Inside the Turk: Understanding Mechanical Turk as a Participant Pool. Current Directions in Psychological Science, 23(3), 184-188. doi:10.1177/0963721414531598

Pew Research Center. (2015a). Americans, Politics and Science Issues. Retrieved from http://www.pewinternet.org/files/2015/07/2015-07-01_science-and-politics_FINAL.pdf

Pew Research Center. (2015b). Public and scientists' views on science and society. Retrieved from http://www.pewinternet.org/files/2015/01/PI_ScienceandSociety_Report_012915.pdf

Prati, G., Pietrantoni, L., \& Zani, B. (2012). The prediction of intention to consume genetically modified food: Test of an integrated psychosocial model. Food Quality and Preference, 25(2), 163-170. doi:10.1016/j.foodqual.2012.02.011

Priest, S. H. (2000). US public opinion divided over biotechnology? Nature biotechnology, 18(9), 939-942.

Qaim, M., \& Kouser, S. (2013). Genetically modified crops and food security. PLoS One, 8(6), e64879. doi:10.1371/journal.pone.0064879

Rains, S. A. (2013). The Nature of Psychological Reactance Revisited: A Meta-Analytic Review. Human Communication Research, 39(1), 47-73. doi:10.1111/j.1468-2958.2012.01443.x

Rains, S. A., \& Turner, M. M. (2007). Psychological Reactance and Persuasive Health Communication: A Test and Extension of the Intertwined Model. Human Communication Research, 33(2), 241-269. doi:10.1111/j.1468-2958.2007.00298.x

Scholderer, J., \& Frewer, L. J. (2003). The Biotechnology Communication Paradox: Experimental Evidence and the Need for a New Strategy. Journal of Consumer Policy, 26(2), 125-157. doi:10.1023/a:1023695519981

Schuldt, J. P., Konrath, S. H., \& Schwarz, N. (2011). "Global warming" or "climate change"?: Whether the planet is warming depends on question wording. Public Opinion Quarterly, 75(1), 115-124. doi:10.1093/poq/nfq073

Schuldt, J. P., \& Roh, S. (2014a). Media Frames and Cognitive Accessibility: What Do "Global Warming" and "Climate Change" Evoke in Partisan Minds? Environmental Communication, 8(4), 529-548. doi:10.1080/17524032.2014.909510

Schuldt, J. P., \& Roh, S. (2014b). Of Accessibility and Applicability: How Heat-Related Cues Affect Belief in "Global Warming" Versus "Climate Change". Social Cognition, 32(3), 217-238.

Schuldt, J. P., Roh, S., \& Schwarz, N. (2015). Questionnaire Design Effects in Climate Change Surveys: Implications for the Partisan Divide. The ANNALS of the American Academy of Political and Social Science, 658(1), 67-85. doi:10.1177/0002716214555066

Spence, A., \& Townsend, E. (2006). Examining consumer behavior toward genetically modified (GM) food in Britain. Risk Anal, 26(3), 657-670. doi:10.1111/j.1539-6924.2006.00777.x 
Taber, C. S., \& Lodge, M. (2006). Motivated skepticism in the evaluation of political beliefs. American Journal of Political Science, 50(3), 755-769. doi:DOI 10.1111/j.15405907.2006.00214.x

Tester, M., \& Langridge, P. (2010). Breeding technologies to increase crop production in a changing world. Science, 327(5967), 818-822. doi:10.1126/science.1183700

Thirtle, C., Beyers, L., Ismael, Y., \& Piesse, J. (2003). Can GM-Technologies Help the Poor? The Impact of Bt Cotton in Makhathini Flats, KwaZulu-Natal. World Development, 31(4), 717-732. doi:10.1016/s0305-750x(03)00004-4

Tjernström, E., \& Tietenberg, T. (2008). Do differences in attitudes explain differences in national climate change policies? Ecological Economics, 65(2), 315-324.

VijayaVenkataRaman, S., Iniyan, S., \& Goic, R. (2012). A review of climate change, mitigation and adaptation. Renewable and Sustainable Energy Reviews, 16(1), 878-897. doi:10.1016/j.rser.2011.09.009

Weber, E. U., \& Stern, P. C. (2011). Public Understanding of Climate Change in the United States. American Psychologist, 66(4), 315-328. doi:10.1037/a0023253

Wheeler, T., \& von Braun, J. (2013). Climate Change Impacts on Global Food Security. Science, 341(6145), 508-513. doi:10.1126/science.1239402

Whitmarsh, L. (2008). What's in a name? Commonalities and differences in public understanding of "climate change" and "global warming". Public Understanding of Science, 18, 401420.

Wiest, S. L., Raymond, L., \& Clawson, R. A. (2015). Framing, partisan predispositions, and public opinion on climate change. Global Environmental Change-Human and Policy Dimensions, 31, 187-198. doi:10.1016/j.gloenvcha.2014.12.006

Zhu, X., \& Xie, X. (2015). Effects of Knowledge on Attitude Formation and Change Toward Genetically Modified Foods. Risk Analysis, 35(5), 790-810. doi:10.1111/risa.12319 
Table 1. Ordinary Least Squares Regression Models (Attitudes toward GM crops as the dependent variable)

\begin{tabular}{|c|c|c|c|c|c|}
\hline \multicolumn{2}{|c|}{ Model 1a: Control as the reference } & \multicolumn{2}{|c|}{ Model 1b: CC as the reference } & \multicolumn{2}{|c|}{ Model 1c: GW as the reference } \\
\hline Variables & $B(S E)$ & Variables & $B(S E)$ & Variables & $B(S E)$ \\
\hline $\mathrm{IC}^{\mathrm{a}}$ & $.43 * *(.15)$ & $\mathrm{IC}$ & $.06(.15)$ & $\mathrm{IC}$ & $.13(.16)$ \\
\hline $\mathrm{CC}^{\mathrm{b}}$ & $.37 * *(.14)$ & GW & $-.07(.15)$ & $\mathrm{CC}$ & $.07(.15)$ \\
\hline $\mathrm{GW}^{\mathrm{c}}$ & $.30 *(.15)$ & Control & $-.37 * *(.14)$ & Control & $-.30 *(.15)$ \\
\hline Ideology & $-.03(.07)$ & Ideology & $.00(.07)$ & Ideology & $-.15(.08)$ \\
\hline IC $x$ ideology & $-.23 *(.10)$ & IC $x$ ideology & $-.26 *(.11)$ & IC $x$ ideology & $-.12(.11)$ \\
\hline CC x ideology & $.03(.10)$ & GW x ideology & $-.15(.11)$ & CC x ideology & $.15(.11)$ \\
\hline GW x ideology & $-.12(.11)$ & Control x ideology & $-.03(.10)$ & Control $\mathrm{x}$ ideology & $.12(.11)$ \\
\hline Sex & $.61 * * *(.13)$ & Sex & $.61 * * *(.13)$ & Sex & $.61 * * *(.13)$ \\
\hline Age & $.01(.00)$ & Age & $.01(.00)$ & Age & $.01(.00)$ \\
\hline Education & $.25^{*}(.12)$ & Education & $.25^{*}(.12)$ & Education & $.25^{*}(.12)$ \\
\hline Income & $.20(.11)$ & Income & $.20(.11)$ & Income & $.20(.11)$ \\
\hline Race & $.29(.15)$ & Race & $.29(.15)$ & Race & $.29(.15)$ \\
\hline Constant & $2.23 * * *(.27)$ & Constant & $2.60 * * *(.27)$ & Constant & $2.53 * * *(.27)$ \\
\hline$R^{2}$ & .06 & $R^{2}$ & .06 & $R^{2}$ & .06 \\
\hline
\end{tabular}

Note. ${ }^{\mathrm{a}} \mathrm{IC}=$ implicit cue condition. ${ }^{\mathrm{b}} \mathrm{CC}=$ "climate change" cue condition. ${ }^{\mathrm{c}} \mathrm{GW}=$ "global warming" cue condition. $* p<.05 . * * p<.01 . * * * p<.001$. 
Table 2. Ordinary Least Squares Regression Models (Intentions to consume GM foods as the dependent variable)

\begin{tabular}{|c|c|c|c|c|c|}
\hline \multicolumn{2}{|c|}{ Model 2a: Control as the reference } & \multicolumn{2}{|c|}{ Model 2b: CC as the reference } & \multicolumn{2}{|c|}{ Model 2c: GW as the reference } \\
\hline Variables & $B(S E)$ & Variables & $B(S E)$ & Variables & $B(S E)$ \\
\hline $\mathrm{IC}^{\mathrm{a}}$ & $.33 *(.16)$ & $\mathrm{IC}$ & $.07(.16)$ & IC & $.28(.17)$ \\
\hline $\mathrm{CC}^{\mathrm{b}}$ & $.26(.15)$ & GW & $-.21(.16)$ & $\mathrm{CC}$ & $.21(.16)$ \\
\hline $\mathrm{GW}^{\mathrm{c}}$ & $.05(.11)$ & Control & $-.26(.15)$ & Control & $-.05(.16)$ \\
\hline Ideology & $.02(.07)$ & Ideology & $.03(.08)$ & Ideology & $-.12(.09)$ \\
\hline IC $x$ ideology & $-.23 *(.11)$ & IC $x$ ideology & $-.24 *(.11)$ & IC $x$ ideology & $-.09(.12)$ \\
\hline CC $\mathrm{x}$ ideology & $.01(.10)$ & GW x ideology & $-.15(.11)$ & CC $x$ ideology & $.15(.11)$ \\
\hline GW x ideology & $-.14(.11)$ & Control $x$ ideology & $-.01(.10)$ & Control $x$ ideology & $.14(.11)$ \\
\hline Sex & $.71 * * *(.13)$ & Sex & $.71 * * *(.13)$ & Sex & $.71 * * *(.13)$ \\
\hline Age & $.00(.00)$ & Age & $.00(.00)$ & Age & $.00(.00)$ \\
\hline Education & $.12(.13)$ & Education & $.12(.13)$ & Education & $.12(.13)$ \\
\hline Income & $.20(.11)$ & Income & $.20(.11)$ & Income & $.20(.11)$ \\
\hline Race & $.44 * *(.16)$ & Race & $.44 * *(.16)$ & Race & $.44 * *(.16)$ \\
\hline Constant & $2.76 * * *(.28)$ & Constant & $3.02 * * *(.28)$ & Constant & $2.81 * * *(.29)$ \\
\hline$R^{2}$ & .05 & $R^{2}$ & .05 & $R^{2}$ & .05 \\
\hline
\end{tabular}

Note. ${ }^{\mathrm{a}} \mathrm{IC}=$ implicit cue condition. ${ }^{\mathrm{b}} \mathrm{CC}=$ "climate change" cue condition. ${ }^{\mathrm{c}} \mathrm{GW}=$ "global warming" cue condition. $* p<.05 . * * p<.01 . * * * p<.001$. 
Table 3. Index of Moderated Mediation

\begin{tabular}{llcccc}
\hline $\begin{array}{l}\text { Dependent } \\
\text { variable }\end{array}$ & Mediator & Index & $S E$ & $\begin{array}{c}\text { 95\% Bootstrap confidence } \\
\text { intervals }\end{array}$ \\
\hline Attitudes toward & Anger & -.03 & .05 & -.12 & .06 \\
GM crops & $\begin{array}{l}\text { Message evaluations } \\
\text { Time spent reading the }\end{array}$ & -.15 & .08 & -.30 & -.00 \\
& $\begin{array}{l}\text { message } \\
\text { Message processing }\end{array}$ & -.01 & .01 & -.04 & .01 \\
& $\begin{array}{l}\text { fluency } \\
\text { Anger }\end{array}$ & -.03 & .01 & -.03 & .01 \\
Intentions to & $\begin{array}{l}\text { Message evaluations } \\
\text { consume GM }\end{array}$ & -.12 & .06 & -.05 & .06 \\
foods & $\begin{array}{l}\text { Time spent reading the } \\
\text { message }\end{array}$ & .00 & .01 & -.00 & -.00 \\
& $\begin{array}{l}\text { Message processing } \\
\text { fluency }\end{array}$ & -.01 & .01 & -.04 & .02 \\
& $\begin{array}{l}\text { Attitudes toward GM } \\
\text { crops }\end{array}$ & -.22 & .09 & -.41 & -.00 \\
\hline
\end{tabular}


Table 4. Ordinary Least Squares Regression Models for Moderated Mediation Analyses

\begin{tabular}{|c|c|c|c|c|c|c|c|c|c|}
\hline \multicolumn{2}{|c|}{$\begin{array}{l}\text { Dependent variable: } \\
\text { Message evaluations }\end{array}$} & \multicolumn{2}{|c|}{$\begin{array}{l}\text { Dependent variable: Attitudes } \\
\text { toward GM crops }\end{array}$} & \multicolumn{2}{|c|}{$\begin{array}{l}\text { Dependent variable: } \\
\text { Intentions to consume GM } \\
\text { foods }\end{array}$} & \multicolumn{2}{|c|}{$\begin{array}{l}\text { Dependent variable: } \\
\text { Intentions to consume GM } \\
\text { foods }\end{array}$} & \multicolumn{2}{|c|}{$\begin{array}{l}\text { Dependent variable: } \\
\text { Intentions to consume GM } \\
\text { foods }\end{array}$} \\
\hline Variables & $B(S E)$ & Variables & $B(S E)$ & Variables & $B(S E)$ & Variables & $B(S E)$ & Variables & $B(S E)$ \\
\hline $\begin{array}{l}\mathrm{IC}^{\mathrm{a}}(\text { ref. }= \\
\left.\mathrm{CC}^{\mathrm{b}}\right)\end{array}$ & $.10(.13)$ & IC (ref. = CC) & $-.01(.12)$ & $\begin{array}{l}\text { IC (ref. = } \\
\mathrm{CC})\end{array}$ & $.03(.14)$ & $\begin{array}{l}\text { IC (ref. = } \\
\text { CC) }\end{array}$ & $.03(.10)$ & $\begin{array}{l}\text { IC (ref. = } \\
\text { CC) }\end{array}$ & $.03(.10)$ \\
\hline $\begin{array}{l}\mathrm{GW}^{\mathrm{c}} \text { (ref. }= \\
\mathrm{CC})\end{array}$ & $-.16(.13)$ & $\begin{array}{l}\mathrm{GW} \text { (ref. = } \\
\mathrm{CC})\end{array}$ & $.06(.12)$ & $\begin{array}{l}\mathrm{GW} \text { (ref. = } \\
\mathrm{CC})\end{array}$ & $-.10(.14)$ & $\begin{array}{l}\mathrm{GW} \text { (ref. = } \\
\mathrm{CC})\end{array}$ & $-.15(.10)$ & $\begin{array}{l}\mathrm{GW} \text { (ref. = } \\
\mathrm{CC} \text { ) }\end{array}$ & $-.15(.10)$ \\
\hline Ideology & $-.09(.06)$ & Ideology & $.07(.06)$ & Ideology & $.09(.07)$ & Ideology & $.03(.05)$ & Ideology & $.03(.05)$ \\
\hline $\begin{array}{l}\text { IC x } \\
\text { ideology }\end{array}$ & $-.19 *(.09)$ & IC $x$ ideology & $-.11(.09)$ & $\begin{array}{l}\text { IC x } \\
\text { ideology }\end{array}$ & $-.11(.10)$ & $\begin{array}{l}\text { IC x } \\
\text { ideology }\end{array}$ & $-.02(.07)$ & $\begin{array}{l}\text { IC x } \\
\text { ideology }\end{array}$ & $-.02(.07)$ \\
\hline \multirow[t]{3}{*}{$\begin{array}{l}\text { GW x } \\
\text { ideology }\end{array}$} & $-.09(.09)$ & $\begin{array}{l}\text { GW x } \\
\text { ideology }\end{array}$ & $-.08(.09)$ & $\begin{array}{l}\text { GW x } \\
\text { ideology }\end{array}$ & $-.09(.10)$ & $\begin{array}{l}\text { GW x } \\
\text { ideology }\end{array}$ & $-.03(.07)$ & $\begin{array}{l}\text { GW x } \\
\text { ideology }\end{array}$ & $-.03(.07)$ \\
\hline & & $\begin{array}{l}\text { Message } \\
\text { evaluations }\end{array}$ & $.76 * * *(.04)$ & $\begin{array}{l}\text { Message } \\
\text { evaluations }\end{array}$ & $.63^{* * *}(.04)$ & $\begin{array}{l}\text { Attitudes } \\
\text { toward GM } \\
\text { crops }\end{array}$ & $.83^{* * *}(.02)$ & $\begin{array}{l}\text { Message } \\
\text { evaluations }\end{array}$ & $-.00(.04)$ \\
\hline & & & & & & & & $\begin{array}{l}\text { Attitudes } \\
\text { toward GM } \\
\text { crops }\end{array}$ & $.83 * * *(.03)$ \\
\hline Sex & $.25 *(.13)$ & Sex & $.50 * * *(.12)$ & Sex & $.75 * * *(.14)$ & Sex & $.34 * * *(.10)$ & Sex & $.34 * * *(.10)$ \\
\hline Age & $.01(.00)$ & Age & $.00(.00)$ & Age & $-.00(.00)$ & Age & $-.01(.00)$ & Age & $-.01(.00)$ \\
\hline Education & $-.14(.12)$ & Education & $.32 * *(.12)$ & Education & $.16(.14)$ & Education & $-.10(.10)$ & Education & $-.10(.10)$ \\
\hline Income & $-.07(.11)$ & Income & $.24 *(.10)$ & Income & $.25 *(.12)$ & Income & $.05(.08)$ & Income & $.05(.08)$ \\
\hline Race & $.10(.15)$ & Race & $.19(.15)$ & Race & $.46^{* *}(.17)$ & Race & $.30 *(.12)$ & Race & $.30 *(.12)$ \\
\hline Constant & $\begin{array}{l}4.04 * * * \\
(.26)\end{array}$ & Constant & $-.45(.29)$ & Constant & $.44(.33)$ & Constant & $.81 * * *(.21)$ & Constant & $.81 * * *(.24)$ \\
\hline$R^{2}$ & .05 & $R^{2}$ & .42 & $R^{2}$ & .29 & $R^{2}$ & .65 & $R^{2}$ & .65 \\
\hline
\end{tabular}

Note. ${ }^{\mathrm{a}} \mathrm{IC}=$ implicit cue condition. ${ }^{\mathrm{b}} \mathrm{CC}=$ "climate change" cue condition. ${ }^{\mathrm{c}} \mathrm{GW}=$ "global warming" cue condition. $* p<.05 . * * p<.01 . * * * p<.001$. 


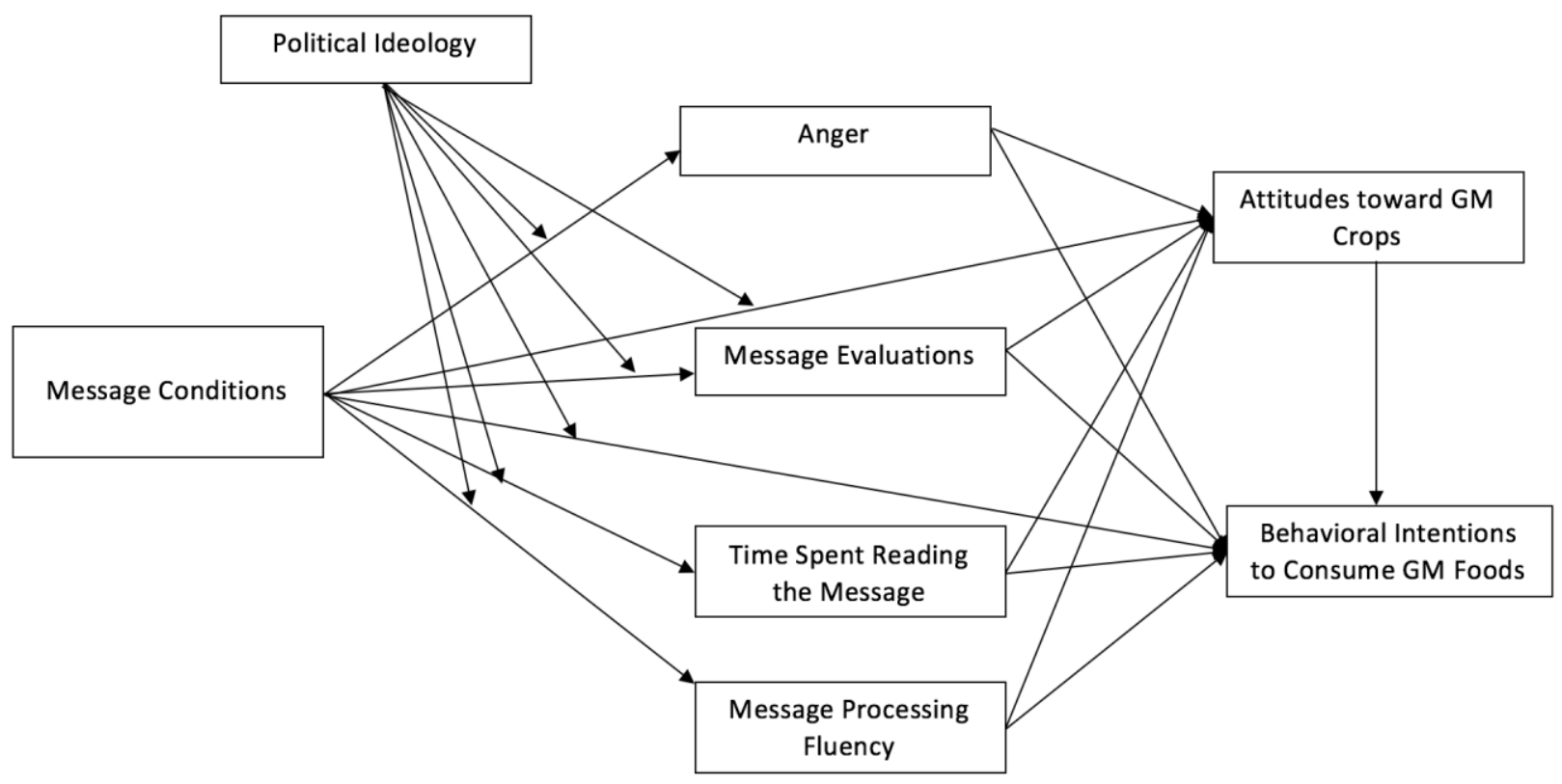

Figure 1. Proposed conceptual model. 


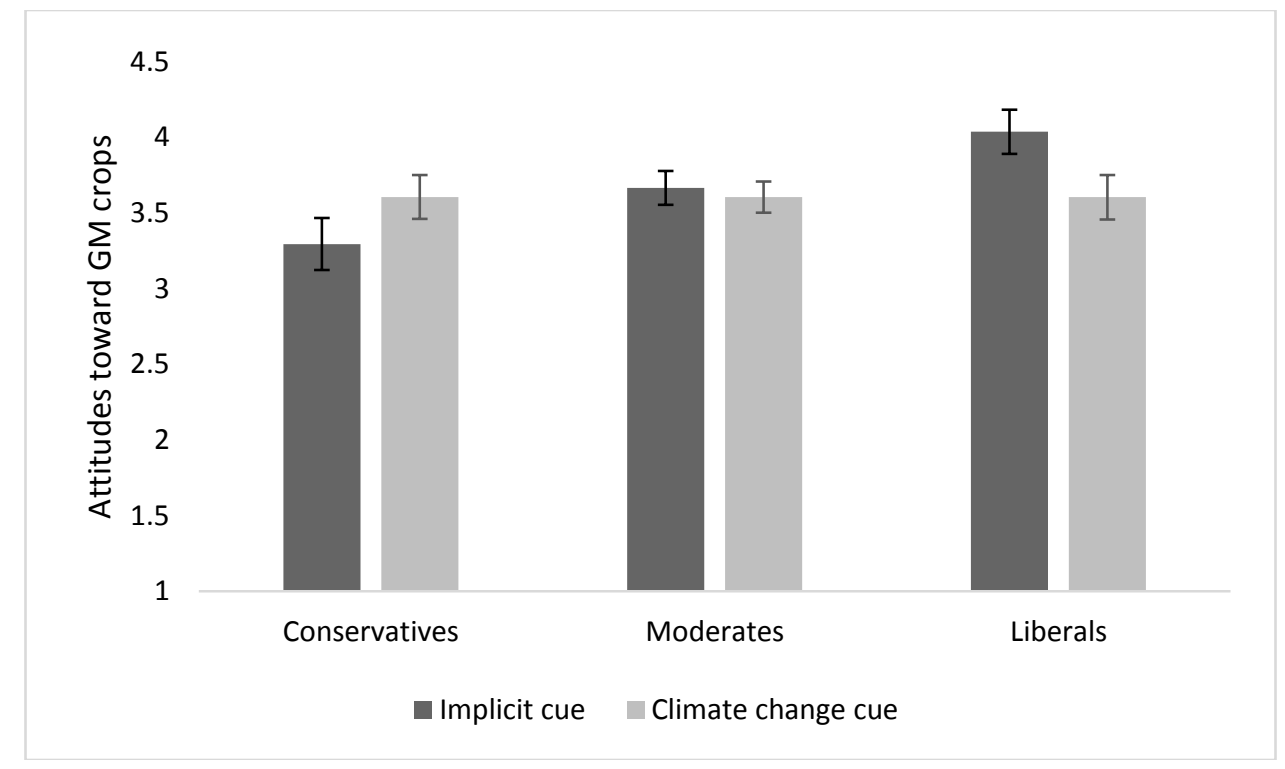

Figure 2. Graph depicting the effect of implicit cue (vs. "climate change" cue) condition on attitudes toward GM crops, by political ideology (conservatives (M+1SD), moderates (M), liberals (M-1SD).

Note. Error bars represent standard errors of the mean. 


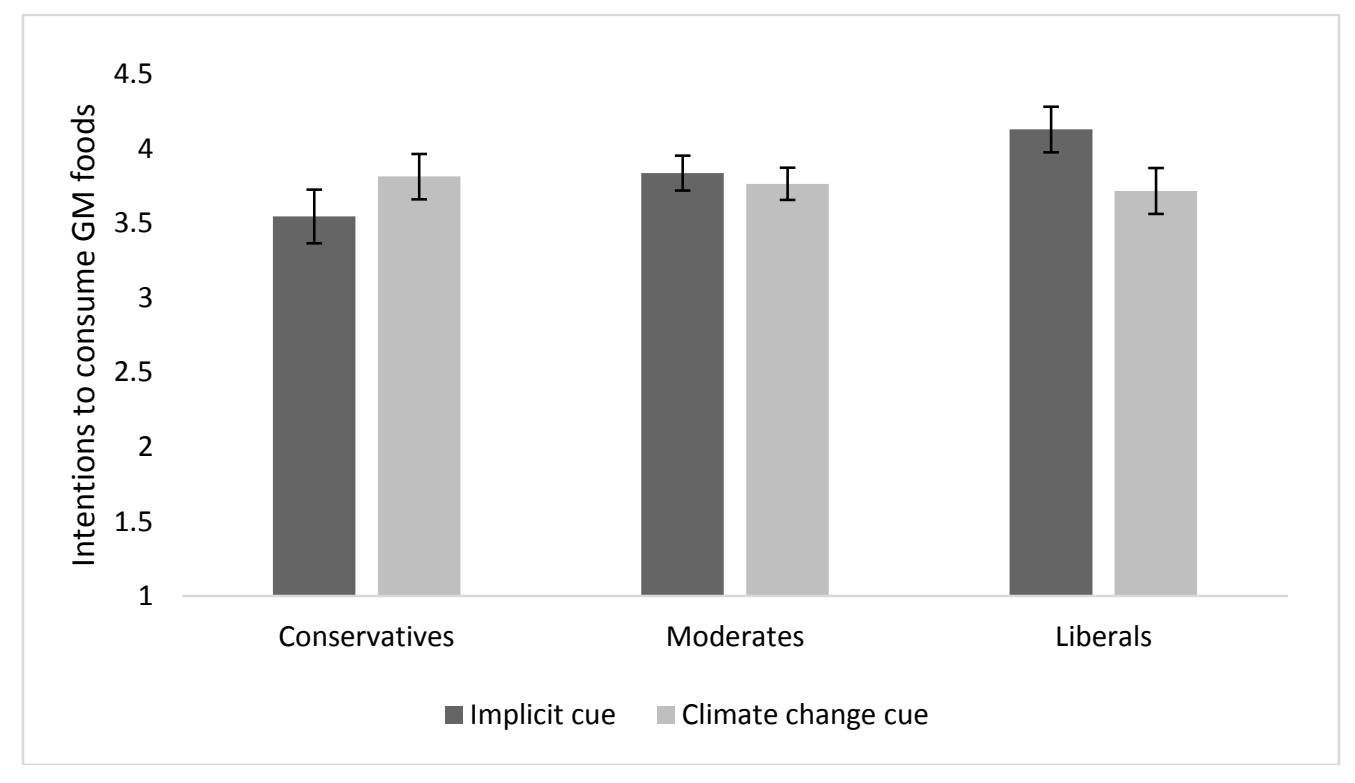

Figure 3. Graph depicting the effect of implicit cue (vs. "climate change" cue) condition on intentions to consume GM foods, by political ideology (conservatives (M+1SD), moderates (M), liberals (M-1SD).

Note. Error bars represent standard errors of the mean. 


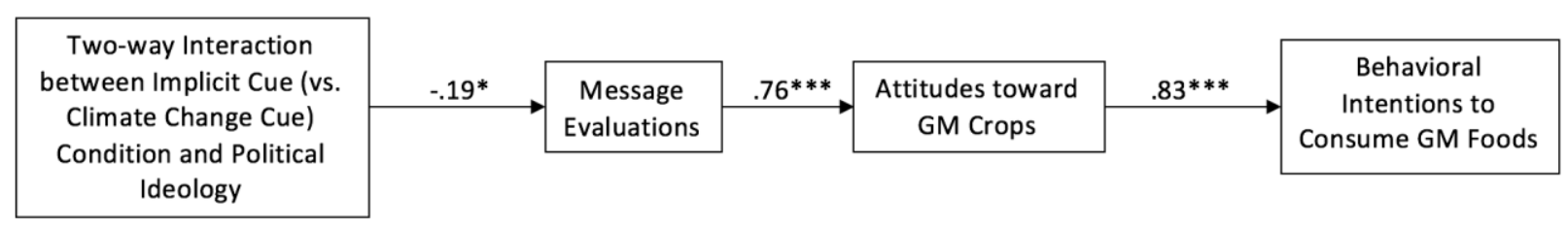

Figure 4. Final Model. Implicit cue (vs. "climate change" cue) condition, political ideology, all covariates, and non-significant paths are not shown to reduce visual clutter.

Note. The statistics represent unstandardized regression coefficients. Total indirect effect $=-.12$ $(95 \%$ confidence interval $=-.2465,-.0004) .{ }^{*} p<.05 ; * * p<.01 ; * * *<.001$. 